\title{
Weak convergence of an iterative algorithm for accretive operators
}

\author{
Hengjun Zhao a , Sun Young Cho ${ }^{\text {b,* }}$ \\ a School of Science, Henan University of Engineering, Zhengzhou 451191, China. \\ ${ }^{b}$ Center for General Education, China Medical University, Taichung, Taiwan.
}

Communicated by P. Kumam

\begin{abstract}
In this paper, an iterative algorithm investigated for m-accretive and inverse-strongly accretive operators. Also, a weak convergence theorem for the sum of two accretive operators is established in a real uniformly convex and q-uniformly smooth Banach space. (C)2017 All rights reserved.
\end{abstract}

Keywords: Accretive operator, zero point, projection, splitting method, weak convergence. 2010 MSC: 47H06, 90C33.

\section{Introduction}

Let $\mathrm{C}$ be a nonempty closed and convex subset of a Hilbert space $\mathrm{H}$ and let $\mathrm{T}: \mathrm{C} \rightarrow 2^{\mathrm{H}}$ be a maximal monotone operator. The corresponding zero problem of operator $T$ is to find $\bar{x} \in \mathrm{C}$ such that $0 \in \mathrm{T} \bar{x}$. An efficient method for solving the problem is the proximal point algorithm, proposed by Martinet [16, 17] and generalized by Rockafellar [22, 23]. In the case that operator $T$ can be decomposed into the sum of two monotone operators, that is, $T=A+B$, where $A$ and $B$ are monotone operators, the problem is reduced to as follows:

$$
\text { find } \bar{x} \in C \text { such that } 0 \in(A+B) \bar{x} \text {. }
$$

The solution set of $(1.1)$ is denoted by $(A+B)^{-1}(0)$. In this paper, we will focus our attention on problem (1.1), which is very general in the sense that it includes, as special cases, convexly constrained linear inverse problems, split feasibility problem, convexly constrained minimization problems, fixed point problems, variational inequalities, Nash equilibrium problem in noncooperative games and others; see, for instance, $[2,3,9,10,19]$ and the references therein.

Because of their importance, forward-backward splitting methods, which were proposed by Passty [18], and, in a dual form for convex programming, by Han and Lou [13], for solving (1.1) have been studied extensively recently; see, for instance, [4, 15, 20, 21, 25] and the references therein. However, most of them are established in the framework of Hilbert spaces. The main reasons are that their iterative

\footnotetext{
*Corresponding author

Email address: ooly61@hotmail.com (Sun Young Cho)
} 
algorithms in the framework of Hilbert spaces are based on the good properties of resolvent operators of monotone operators, but these properties are not available in the framework of general Banach spaces.

The aim of this paper is to present a forward-backward splitting method for solving (1.1) in the framework of real Banach spaces. The main tool in this article is Xu's inequalities and the framework of the spaces is real uniformly convex and q-uniformly smooth Banach spaces. The paper is organized in the following way. In Section 2, we present the preliminaries that are needed in our work. In Section 3, we present a theorem of weak convergence for m-accretive and inverse-strongly accretive operators. In Section 4, some sub-results are presented in the framework of real Hilbert spaces.

\section{Preliminaries}

Let $E$ be a real Banach space and let $E^{*}$ be the dual space of $E$. Let $w: R^{+} \rightarrow R^{+}$, where $R^{+}$denotes the set of nonnegative real numbers, be a continuous strictly increasing function such that $w(0)=0$ and $\lim _{s \rightarrow \infty} \mathcal{W}(s)=\infty$, we associate with it a possibly multivalued generalized duality map $\mathfrak{J}_{g}: E \rightarrow 2^{E^{*}}$ defined as $\mathfrak{J}_{\mathrm{g}}(x):=\left\{y \in E^{*}: y(x)=\|x\| w(\|x\|), w(\|x\|)=\|y\|\right\}$, for all $x \in E$. In this paper, we use the generalized duality map associated with the gauge function $w(t)=t^{q-1}$ for $q>1$,

$$
\mathfrak{J}_{\mathrm{q}}:=\left\{\mathrm{y} \in \mathrm{E}^{*}:\langle\mathrm{y}, \mathrm{x}\rangle=\|\mathrm{x}\|^{\mathrm{q}},\|\mathrm{y}\|=\|x\|^{\mathrm{q}-1}\right\}, \quad \forall x \in \mathrm{E} .
$$

In particular, $g(t)=t$, we write $\mathfrak{J}$ for $\mathfrak{J}_{g}$ and call $\mathfrak{J}$ the normalized duality mapping.

Let $S_{E}=\{x \in E:\|x\|=1\}$. $E$ is said to be smooth or said to be have a Gâteaux differentiable norm if and only if the limit

$$
\lim _{t \rightarrow 0}(\|x+t y\|-\|x\|) / t
$$

exists for each $x, y \in S_{E}$. $E$ is said to be uniformly smooth or said to have a uniformly Fréchet differentiable norm if the limit is attained uniformly for $x, y \in S_{E}$. $E$ is said to have a uniformly Gâteaux differentiable norm if for each $y \in S_{E}$, the limit is attained uniformly for all $x \in S_{E}$.

Let $M_{E}:[0,1) \rightarrow[0,1)$ be the modulus of smoothness of $E$ defined by

$$
M_{\mathrm{E}}^{\mathrm{t}}=\sup \left\{\frac{\|x+y\|+\|x-y\|-2}{2}: x \in S_{\mathrm{E}},\|y\| \leqslant \mathrm{t}\right\} .
$$

A Banach space $E$ is said to be uniform smoothness if $M_{E}(t) \rightarrow 0$ as $t \rightarrow 0$. Let $q>1$. A Banach space $E$ is said to be a q-uniformly smooth Banach, if and only if there exists a fixed constant $c>0$ such that $M_{E}(t) \leqslant c t^{q}$. It is known that $E$ is uniformly smooth if and only if the norm of $E$ is uniformly Fréchet differentiable. If $E$ is a $q$-uniform smoothness Banach space, then $q \leqslant 2$ and $E$ is uniformly smooth, and hence the norm of $E$ is uniformly Fréchet differentiable, in particular, the norm of $E$ is Fréchet differentiable.

Recall that the modulus of convexity of $E$ is defined by

$$
\epsilon^{\mathrm{E}}(\delta)=\inf \left\{1-\left\|\frac{x+y}{2}\right\|:\|x-y\| \geqslant \delta,\|x\| \leqslant 1,\|y\| \leqslant 1\right\}, \quad \forall \delta \in[0,2] .
$$

$\mathrm{E}$ is said to be uniformly convex if $\epsilon^{\mathrm{E}}(0)=0$, and $\epsilon(\delta)>0$ for all $0<\delta \leqslant 2$. It is known that a Hilbert space is 2 -uniformly convex, while $L_{p}$ is $\max \{2, p\}$-uniformly convex for every $p>1$.

Typical examples of both uniformly convex and uniformly smooth Banach spaces are $L_{p}$, where $p>1$. More precisely, $\mathrm{L}_{p}$ is $\min \{\mathrm{p}, 2\}$-uniformly smooth for $\mathrm{p}>1$.

Recall that a Banach space $E$ is said to be strictly convex if and only if $\|x+y\|<2$ for all $x, y \in S_{E}$ with $x \neq y$.

Let $T$ be a mapping on $E$. The fixed point set of $T$ is denoted by $F(T)$. Recall that $T$ is said to be contractive iff there exists a constant $k \in(0,1)$ such that

$$
\|\mathrm{T} x-\mathrm{T} y\| \leqslant \kappa\|x, y\|, \quad \forall x, y \in C .
$$


We know that the sequence generated in the Picard iterative algorithm $x_{n+1}=T x_{n}$ converges to the unique fixed point of $T$.

Recall that $\mathrm{T}$ is said to be nonexpansive iff

$$
\|T x-T y\| \leqslant\|x-y\|, \quad \forall x, y \in C .
$$

For the class of nonexpansive mappings, their fixed point sets may be empty.

Example $2.1([1])$. Let $H=L^{1}[0,1]$ and let $C:=\left\{f \in L^{1}[0,1]: \int_{0}^{1} f(x) d x=1,0 \leqslant f \leqslant 2\right\}$. Define $\|f\|_{1}=$ $\int_{0}^{1}|f(t)| d t$. Then $C$ is weakly compact and convex.

$$
(T f)(t)= \begin{cases}\min \{2 f(2 t), 2\}, & 0 \leqslant t \leqslant \frac{1}{2} \\ \min \{2 f(2 t-1)-2,0\}, & \frac{1}{2}<t \leqslant 1\end{cases}
$$

Then $\mathrm{T}$ is a nonexpansive mapping $\mathrm{C} \rightarrow \mathrm{C}$ without a fixed point.

Example 2.2 ([1]). Let $H=l^{1}$, i.e., all sequences $\left\{x_{n}\right\}$ such that $\sum\left|x_{n}\right|<\infty$

$$
\left\|x_{n}\right\|_{1}=\sum\left|x_{n}\right|
$$

Let $T: l^{1} \rightarrow l^{1}$ be the shift operator $T x_{n}=\left(0, x_{1}, x_{2}, \cdots\right)$,

$$
C:=\left\{\left\{x_{n}\right\}: x_{n} \geqslant 0,\left\|x_{n}\right\|_{1}=1\right\} .
$$

Then $\mathrm{T}: \mathrm{C} \rightarrow \mathrm{C}$ is a nonexpansive mapping without a fixed point.

It is known if $\mathrm{C}$ is convex bounded and closed, then the set of fixed points is not empty. Iterative methods are efficient to study fixed point problems of nonexpansive mappings; see [11, 24, 28] and the references therein. If $\mathrm{H}$ is a Banach space instead of a Hilbert space, then we have the following approximate fixed point result. Let $\mathrm{C}$ be a bounded closed convex subset of a Banach space, and $\mathrm{T}: \mathrm{C} \rightarrow \mathrm{C}$ is nonexpansive, then $T$ has an approximate fixed point, i.e., there exists a sequence $x_{n} \in C$ such that $\left\|T x_{n}-x_{n}\right\| \rightarrow 0$. Indeed, for each $1>\lambda>0$, define $T_{\lambda} x=T \lambda x$. Then $\lambda\|x-y\| \geqslant\left\|T_{\lambda} x-T_{\lambda} y\right\|$. Using Banach contractive principle, there exists $x_{\lambda} \in C$ such that $T_{\lambda} x_{\lambda}=x_{\lambda}$. Now

$$
\left\|T x_{\lambda}-x_{\lambda}\right\|=\left\|T x_{\lambda}-T_{\lambda} x_{\lambda}\right\|=\left\|T x_{\lambda}-T \lambda x_{\lambda}\right\| \leqslant(1-\lambda)\left\|x_{\lambda}\right\| \rightarrow 0 .
$$

Then T has an approximate fixed point.

However, for the class of nonexpansive mappings, Picard iterative algorithm fails to converge for nonexpansive mappings even with fixed points. Mann iterative algorithm has been recently investigated to study fixed point problems of nonexpansive mappings. The convex combination between nonexpansive mappings and the identity mapping improves the regularization of the original nonexpansive mappings. Recall that the Mann's iterative process generates a sequence $\left\{x_{n}\right\}$ in the manner

$$
x_{0} \in C, \quad x_{n+1}=\alpha_{n} T x_{n}+\left(1-\alpha_{n}\right) x_{n}, \quad \forall n \geqslant 0,
$$

where $\left\{\alpha_{n}\right\}$ is a sequence in $(0,1)$.

We have the following celebrated result. Let $\mathrm{H}$ be a Hilbert space and let $\mathrm{C}$ be a closed and convex subset of $\mathrm{H}$. Let $\mathrm{T}: \mathrm{C} \rightarrow \mathrm{C}$ be a nonexpansive mapping with a nonempty fixed point set. Let $\left\{x_{n}\right\}$ be a sequence generated in the Mann's iterative process. Assume that $\sum_{n=0}^{\infty} \alpha_{n}\left(1-\alpha_{n}\right)=\infty$. Then $\left\{x_{n}\right\}$ converges weakly to a point in $F(T)$. We also remark here that the above result is still valid in the framework of uniformly convex Banach spaces with a Fréchet differentiable norm.

Let $I$ denote the identity operator on $E$. An operator $A \subset E \times E$ with domain $D(A)=\{z \in E: A z \neq \emptyset\}$ and range $R(A)=\cup\{A z: z \in D(A)\}$ is said to be accretive if, for $t>0$ and $x, y \in D(A)$,

$$
\|x-y\| \leqslant\|x-y+t(u-v)\|, \quad \forall u \in A x, v \in A y .
$$


$A$ is said to be $\phi$-strongly accretive if, for $x, y \in D(A)$, there exists a $\mathfrak{j}_{\mathbf{q}}\left(x_{1}-x_{2}\right) \in \mathfrak{J}_{\mathbf{q}}\left(x_{1}-x_{2}\right)$ such that

$$
\left\langle u-v, j_{\mathfrak{q}}(x-y)\right\rangle \geqslant \phi(\|x-y\|)\|x-y\|, \quad \forall u \in A x, v \in A y .
$$

It is clear that every $\phi$-strongly accretive operator is accretive. It follows from Kato [14] that $A$ is accretive if and only if, for $x, y \in D(A)$, there exists $\mathfrak{j}_{q}\left(x_{1}-x_{2}\right)$ such that

$$
\left\langle u-v, j_{\mathbf{q}}(x-y)\right\rangle \geqslant 0 .
$$

An accretive operator $A$ is said to be $m$-accretive if $R(I+r A)=E$ for all $r>0$. In a real Hilbert space, an operator $A$ is $m$-accretive if and only if $A$ is maximal monotone. In this paper, we use $A^{-1}(0)$ to denote the set of zeros of $A$.

For an accretive operator $A$, we can define a firmly nonexpansive single-valued mapping $J_{r}^{A}: R(I+$ $r A) \rightarrow D(A)$ by $J_{r}^{A}=(I+r A)^{-1}$ for each $r>0$, which is called the resolvent operator of $A$.

Recall that a single-valued operator $A: E \rightarrow E$ is said to be $\alpha$-strongly accretive if there exists a constant $\alpha>0$ and some $\mathfrak{j}_{\mathrm{q}}(x-y) \in \mathfrak{J}_{\mathrm{q}}(x-y)$ such that

$$
\left\langle A x-A y, j_{q}(x-y)\right\rangle \geqslant \alpha\|x-y\|^{q}, \quad \forall x, y \in E .
$$

$A: E \rightarrow E$ is said to be $\alpha$-inverse strongly accretive if there exist a constant $\alpha>0$ and some $j_{q}(x-y) \in$ $\mathfrak{J}_{q}(x-y)$ such that

$$
\left\langle A x-A y, j_{\mathbf{q}}(x-y)\right\rangle \geqslant \alpha\|A x-A y\|^{q}, \quad \forall x, y \in E .
$$

The following lemmas also play an important role in this article.

Lemma 2.3 ([25]). Let $\mathrm{E}$ be a real q-uniformly smooth Banach space. Then the following inequality holds: $(\| x+$ $\left.y\left\|^{\mathrm{q}}-\right\| x \|^{\mathrm{q}}\right) / \mathrm{q} \leqslant\left\langle y, \mathfrak{J}_{\mathrm{q}}(\mathrm{x}+\mathrm{y})\right\rangle$ and

$$
\left(\|x+y\|^{q}-\|x\|^{q}-K_{q}\|y\|^{q}\right) / q \leqslant\left\langle y, \mathfrak{J}_{q}(x)\right\rangle, \quad \forall x, y \in E,
$$

where $\mathrm{K}_{\mathrm{q}}$ is some positive constant.

Lemma 2.4 ([21]). Let $\mathrm{E}$ be a real Banach space and let $\mathrm{C}$ be a nonempty closed and convex subset of $\mathrm{E}$. Let $\mathrm{A}: \mathrm{C} \rightarrow \mathrm{E}$ be a single-valued operator and let $\mathrm{B}: \mathrm{E} \rightarrow 2^{\mathrm{E}}$ be an $\mathrm{m}$-accretive operator. Then

$$
(A+B)^{-1}(0)=F\left(J_{a}^{B}(I-a A)\right),
$$

where $\mathrm{J}_{\mathrm{a}}^{\mathrm{B}}$ is the resolvent operator of $\mathrm{B}$ for $\mathrm{a}>0$.

Lemma 2.5 ([27]). Let $\mathrm{p}>1$ and $\mathrm{r}>0$ be two fixed real numbers. Then a Banach space $\mathrm{E}$ is uniformly convex if and only if there exists a continuous strictly increasing convex function $\varphi:[0, \infty) \rightarrow[0, \infty)$ with $\varphi(0)=0$ such that

$$
\left(a^{p}(1-a)+(1-a)^{p} a\right) \varphi(\|x-y\|) \leqslant a\|x\|^{p}+(1-a)\|y\|^{p}-\|a x+(1-a) y\|^{p}
$$

for all $x, y \in\{x \in E:\|x\| \leqslant r\}$ and $a \in[0,1]$.

Lemma 2.6 ([7]). Let $\mathrm{E}$ be a real uniformly convex Banach space and let $\mathrm{C}$ be a nonempty closed convex and bounded subset of $\mathrm{E}$. Then there is a strictly increasing and continuous convex function $\psi:[0, \infty) \rightarrow[0, \infty)$ with $\varphi(0)=0$ such that, for every Lipschitzian continuous mapping $\mathrm{T}: \mathrm{C} \rightarrow \mathrm{C}$ and for all $\mathrm{x}, \mathrm{y} \in \mathrm{C}$ and $\mathrm{t} \in[0,1]$, the following inequality holds:

$$
\mathrm{L} \psi^{-1}\left(\|x-y\|-\mathrm{L}^{-1}\|\mathrm{~T} x-\mathrm{T} y\|\right) \geqslant\|\mathrm{T}(\mathrm{t} x+(1-\mathrm{t}) \mathrm{y})-(\mathrm{tT} x+(1-\mathrm{t}) \mathrm{T} y)\|,
$$

where $\mathrm{L} \geqslant 1$ is the Lipschitz constant of $\mathrm{T}$. 
Lemma 2.7 ([6]). Let $\mathrm{C}$ be a nonempty convex closed subset of be a uniformly convex Banach space. If $\mathrm{T}: \mathrm{C} \rightarrow \mathrm{C}$ is nonexpansive, then we have the following implication

$$
\left\{\begin{array}{l}
x_{n} \rightarrow z \\
x_{n}-T x_{n} \rightarrow 0,
\end{array} \Longrightarrow T z=z\right.
$$

Lemma 2.8 ([12]). Let $\mathrm{E}$ be a uniformly convex Banach space. Let $\mathrm{E}^{*}$ be the dual space of $\mathrm{E}$ with the Kadec-Klee property. Assume that $\left\{x_{n}\right\}$ is a bounded sequence such that the limit $\left\|q_{1} x_{n}-q_{3}+(1-a) q_{2}\right\|$ exists as $n \rightarrow \infty$ for all $\mathrm{q} \in[0,1]$ and $\mathrm{q}_{2}, \mathrm{q}_{3} \in \omega_{w}\left(x_{n}\right)$, where $\omega_{w}\left(x_{n}\right):=\left\{x: \exists x_{n_{i}} \rightarrow x\right\}$ denotes the weak $w$-limit set of $\left\{x_{n}\right\}$. Then $\omega_{w}\left(x_{n}\right)$ is a singleton set.

\section{Main results}

Theorem 3.1. Let $\mathrm{C}$ be a nonempty convex and closed subset of a real uniformly convex and q-uniformly smooth Banach space $\mathrm{E}$. Let $\mathrm{K}_{\mathrm{q}}$ be the smooth constant $\mathrm{E}$. Let $\mathrm{B}: \operatorname{Dom}(\mathrm{B}) \subset \mathrm{C} \rightarrow 2^{\mathrm{E}}$ be an m-accretive operator and let $\mathrm{A}: \mathrm{C} \rightarrow \mathrm{E}$ be an $\alpha$-inverse strongly accretive operator. Assume $(\mathrm{B}+\mathrm{A})^{-1}(0) \neq \emptyset$. Let $\left\{\mathrm{x}_{\mathrm{n}}\right\}$ be a sequence defined by: $\mathrm{x}_{0} \in \mathrm{C}$ and

$$
\left\{\begin{array}{l}
z_{n} \approx\left(I+r_{n} B\right)^{-1}\left(x_{n}-r_{n} A x_{n}\right), \\
x_{n+1}=\left(1-\alpha_{n}\right) z_{n}+\alpha_{n} x_{n}, \quad \forall n \geqslant 0
\end{array}\right.
$$

where the criterion for the approximate computation of $z_{n}$ is $\left\|\left(I+r_{n} B\right)^{-1}\left(x_{n}-r_{n} A x_{n}\right)-z_{n}\right\| \leqslant e_{n}$, and $\left\{\alpha_{n}\right\}$ and $\left\{r_{n}\right\}$ are real sequences satisfying the following restrictions: $\sum_{i=0}^{\infty} e_{n}<\infty, 0 \leqslant \alpha_{n} \leqslant \alpha<1$, and $0<r \leqslant$ $\mathrm{K}_{\mathrm{q}} \mathrm{r}_{\mathrm{n}}^{\mathrm{q}-1} \leqslant \mathrm{r}^{\prime}<\mathrm{q} \alpha$. Then $\left\{\mathrm{x}_{\mathrm{n}}\right\}$ converges weakly to some zero of $\mathrm{B}+\mathrm{A}$.

Proof. First, we show iterative sequence $\left\{x_{n}\right\}$ is bounded. Fixing $p \in(A+B)^{-1}(0)$, one finds

$$
\begin{aligned}
\left\|x_{n+1}-p\right\| & \leqslant \alpha_{n}\left\|x_{n}-p\right\|+\left(1-\alpha_{n}\right)\left\|z_{n}-p\right\| \\
& \leqslant\left(1-\alpha_{n}\right)\left\|J_{r_{n}}^{B}\left(x_{n}-r_{n} A x_{n}\right)-z_{n}\right\|+\left(1-\alpha_{n}\right)\left\|J_{r_{n}}^{B}\left(x_{n}-r_{n} A x_{n}\right)-p\right\|+\alpha_{n}\left\|x_{n}-p\right\| \\
& \leqslant\left(1-\alpha_{n}\right)\left\|\left(x_{n}-r_{n} A x_{n}\right)-\left(p-r_{n} A\right) p\right\|+\left(1-\alpha_{n}\right)\left\|e_{n}\right\|+\alpha_{n}\left\|x_{n}-p\right\| .
\end{aligned}
$$

From Lemma 2.3 and the restriction imposed on $\left\{r_{n}\right\}$, one has

$$
\begin{aligned}
\left\|\left(I-r_{n} A\right) x-\left(I-r_{n} A\right) y\right\|^{q} & \leqslant K_{q} r_{n}^{q}\|A x-A y\|^{q}+\|x-y\|^{q}-q r_{n}\left\langle A x-A y, \mathfrak{J}_{q}(x-y)\right\rangle \\
& \leqslant K_{q} r_{n}^{q}\|A x-A y\|^{q}+\|x-y\|^{q}-q r_{n} \alpha\|A x-A y\|^{q} \\
& =\left(K_{q} r_{n}^{q-1}-q \alpha\right) r_{n}\|A x-A y\|^{q}+\|x-y\|^{q} \leqslant\|x-y\|^{q} .
\end{aligned}
$$

Hence, we have

$$
\left\|x_{n+1}-p\right\| \leqslant\left\|x_{n}-p\right\|+\left\|e_{n}\right\| .
$$

Since $\sum_{i=0}^{\infty} e_{n}<\infty$, we find that the limit of $\left\|x_{n}-p\right\|$ exists as $n \rightarrow \infty$, in particular, $\left\{x_{n}\right\}$ is a bounded sequence. Putting $y_{n}=J_{r_{n}}^{B}\left(x_{n}-r_{n} A x_{n}\right)$, we find from Lemma 2.5 that

$$
\begin{aligned}
\left\|y_{n}-p+\left(\left(I-r_{n} A\right) x_{n}-\left(I-r_{n} A\right) p\right)\right\|^{q}= & 2^{q}\left\|\frac{1}{2}\left(y_{n}-p\right)+\frac{1}{2}\left(\left(I-r_{n} A\right) x_{n}-\left(I-r_{n} A\right) p\right)\right\|^{q} \\
\leqslant & 2^{q-1}\left\|y_{n}-p\right\|^{q}+2^{q-1}\left\|\left(I-r_{n} A\right) x_{n}-\left(I-r_{n} A\right) p\right\|^{q} \\
& -\varphi\left(\left\|\left(y_{n}-p\right)-\left(\left(I-r_{n} A\right) x_{n}-\left(I-r_{n} A\right) p\right)\right\|\right) \\
\leqslant & 2^{q}\left\|\left(I-r_{n} A\right) x_{n}-\left(I-r_{n} A\right) p\right\|^{q} \\
& -\varphi\left(\left\|\left(y_{n}-p\right)-\left(\left(I-r_{n} A\right) x_{n}-\left(I-r_{n} A\right) p\right)\right\|\right) .
\end{aligned}
$$


Since $B$ is an m-accretive operator, we find that

$$
\begin{aligned}
\left\|y_{n}-p\right\|^{q} \leqslant & \left\|\frac{r_{n}}{2}\left(\frac{x_{n}-r_{n} A x_{n}-y_{n}}{r_{n}}-\frac{\left(I-r_{n} A\right) p-p}{r_{n}}\right)+y_{n}-p\right\|^{q} \\
= & \left\|\frac{\left(y_{n}-p\right)+\left(I-r_{n} A\right) x_{n}-\left(I-r_{n} A\right) p}{2}\right\|^{q} \\
= & \left\|\frac{1}{2}\left(y_{n}-p\right)+\frac{1}{2}\left(\left(I-r_{n} A\right) x_{n}-\left(I-r_{n} A\right) p\right)\right\|^{q} \\
\leqslant & \left\|x_{n}-p\right\|^{q}-\left(\alpha q-K_{q} r_{n}^{q-1}\right) r_{n}\left\|A x_{n}-A p\right\|^{q} \\
& -\frac{1}{2^{q}} \varphi\left(\left\|\left(y_{n}-p\right)-\left(\left(I-r_{n} A\right) x_{n}-\left(I-r_{n} A\right) p\right)\right\|\right) .
\end{aligned}
$$

Since $\|\cdot\|^{q}$ is a convex function, we find that

$$
\begin{aligned}
\left\|x_{n+1}-p\right\|^{\mathrm{q}} \leqslant & \left(1-\alpha_{n}\right)\left\|z_{n}-p\right\|^{\mathrm{q}}+\alpha_{n}\left\|x_{n}-p\right\|^{\mathrm{q}} \\
\leqslant & \left(1-\alpha_{n}\right)\left\|y_{n}-p+z_{n}-y_{n}\right\|^{\mathrm{q}}+\alpha_{n}\left\|x_{n}-p\right\|^{\mathrm{q}} \\
\leqslant & \left(1-\alpha_{n}\right)\left(\left\|y_{n}-p\right\|^{\mathrm{q}}+q\left\langle z_{n}-y_{n}, \mathfrak{J}_{\mathrm{q}}\left(z_{n}-p\right)\right\rangle\right)+\alpha_{n}\left\|x_{n}-p\right\|^{\mathrm{q}} \\
\leqslant & \left(1-\alpha_{n}\right)\left\|y_{n}-p\right\|^{\mathrm{q}}+\mathrm{q}\left\langle z_{n}-y_{n}, \mathfrak{J}_{\mathrm{q}}\left(z_{n}-p\right)\right\rangle+\alpha_{n}\left\|x_{n}-p\right\|^{\mathrm{q}} \\
\leqslant & \left(1-\alpha_{n}\right)\left\|y_{n}-p\right\|^{\mathrm{q}}+q\left\|e_{n}\right\|\left\|z_{n}-p\right\|^{\mathrm{q}-1}+\alpha_{n}\left\|x_{n}-p\right\|^{\mathrm{q}} \\
\leqslant & \left\|x_{n}-p\right\|^{\mathrm{q}}-\left(1-\alpha_{n}\right) \frac{1}{2^{q}} \varphi\left(\left\|\left(y_{n}-p\right)-\left(\left(I-r_{n} A\right) x_{n}-\left(I-r_{n} A\right) p\right)\right\|\right) \\
& -\left(1-\alpha_{n}\right)\left(\alpha q-\kappa_{q} r_{n}^{q-1}\right) r_{n}\left\|A x_{n}-A p\right\|^{q}+q\left\|e_{n}\right\|\left\|z_{n}-p\right\|^{q-1} .
\end{aligned}
$$

It follows from the restrictions imposed on $\left\{\alpha_{n}\right\}$ and $\left\{r_{n}\right\}$ that

$$
\lim _{n \rightarrow \infty}\left\|A p-A x_{n}\right\|=0
$$

and

$$
\lim _{n \rightarrow \infty}\left\|y_{n}-x_{n}+r_{n}\left(A x_{n}-A p\right)\right\|=0
$$

Note the fact

$$
\left\|y_{n}-x_{n}\right\| \leqslant\left\|y_{n}+r_{n}\left(A x_{n}-r_{n} A p\right)-x_{n}\right\|+r_{n}\left\|A x_{n}-A p\right\| .
$$

It follows from (3.1) and (3.2) that

$$
\lim _{n \rightarrow \infty}\left\|J_{r_{n}}^{B}\left(x_{n}-r_{n} A x_{n}\right)-x_{n}\right\|=0
$$

Notice that

$$
\left\langle r_{n}\left(x_{n}-J_{r}^{B}(I-r A) x_{n}\right)-r\left(x_{n}-J_{r_{n}}^{B}\left(I-r_{n} A\right) x_{n}\right), \mathfrak{J}_{q}\left(J_{r}^{B}(I-r A) x_{n}-J_{r_{n}}^{B}\left(I-r_{n} A\right) x_{n}\right)\right\rangle \geqslant 0 .
$$

Hence, we find that

$$
\begin{aligned}
\| x_{n} & -J_{r_{n}}\left(I-r_{n} A\right) x_{n}\|\| J_{r}(I-r A) x_{n}-J_{r_{n}}^{B}\left(I-r_{n} A\right) x_{n} \|^{q-1} \\
& \geqslant \frac{r_{n}-r}{r_{n}}\left\langle x_{n}-J_{r_{n}}^{B}\left(I-r_{n} A\right) x_{n}, J_{q}\left(J_{r}^{B}(I-r A) x_{n}-J_{r_{n}}^{B}\left(I-r_{n} A\right) x_{n}\right)\right\rangle \\
& \geqslant\left\|J_{r}^{B}(I-r A) x_{n}-J_{r_{n}}^{B}\left(I-r_{n} A\right) x_{n}\right\|^{q} .
\end{aligned}
$$

This implies that $\left\|J_{r}^{B}(I-r A) x_{n}-J_{r_{n}}^{B}\left(I-r_{n} A\right) y_{n}\right\| \leqslant\left\|x_{n}-J_{r_{n}}^{B}\left(I-r_{n} A\right) x_{n}\right\|$. It follows that

$$
\begin{aligned}
\left\|J_{r}^{B}(I-r A) x_{n}-x_{n}\right\| & \leqslant\left\|J_{r}^{B}(I-r A) x_{n}-J_{r_{n}}^{B}\left(I-r_{n} A\right) x_{n}\right\|+\left\|J_{r_{n}}\left(I-r_{n} A\right) x_{n}-x_{n}\right\| \\
& \leqslant 2\left\|J_{r_{n}}\left(I-r_{n} A\right) x_{n}-x_{n}\right\| .
\end{aligned}
$$


From (3.3), we arrive at

$$
\lim _{n \rightarrow \infty}\left\|J_{r}^{B}\left(x_{n}-r A x_{n}\right)-x_{n}\right\|=0 .
$$

Define mappings $\mathrm{T}_{\mathrm{n}}: \mathrm{C} \rightarrow \mathrm{C}$ by

$$
\mathrm{T}_{\mathrm{n}}:=\alpha_{\mathrm{n}} \mathrm{I}+\left(1-\alpha_{\mathrm{n}}\right) \mathrm{J}_{\mathrm{r}_{\mathrm{n}}}^{\mathrm{B}}\left(\mathrm{I}-\mathrm{r}_{\mathrm{n}} \mathrm{A}\right), \quad \forall x \in \mathrm{C},
$$

where I is the identity mapping and set

$$
S_{n, m}=T_{n+m-1} T_{n+m-2} \cdots T_{n}, \quad \forall n, m \geqslant 1 .
$$

Then $S_{n, m}$ is nonexpansive and $S_{n, m} x_{n}=x_{n+m}$. For all $t \in[0,1]$ and $n, m \geqslant 1$, put

$$
a_{n}(t)=\left\|u-t x_{n}-(1-t) v\right\|,
$$

and

$$
b_{n, m}=\left\|S_{n, m}\left(t x_{n}+(1-t) v\right)-\left(t x_{n+m}+(1-t) v\right)\right\|,
$$

where $v$ and $u$ are in $(A+B)^{-1}(0)$. Using Lemma 2.6, we find that

$$
\begin{aligned}
b_{n, m} & \leqslant \psi^{-1}\left(\left\|x_{n}-v\right\|-\left\|S_{n, m} x_{n}-S_{n, m} v\right\|\right) \\
& =\psi^{-1}\left(\left\|x_{n}-v\right\|-\left\|x_{n+m}-v-S_{n, m} v+v\right\|\right) \\
& \leqslant \psi^{-1}\left(\left\|v-x_{n}\right\|-\left(\left\|x_{n+m}-v\right\|-\left\|S_{n, m} v-v\right\|\right)\right) .
\end{aligned}
$$

It follows that $\left\{b_{n, m}\right\}$ converges uniformly to zero as $n \rightarrow \infty$ for all $m \geqslant 1$. It also follows from (3.4) that

$$
\begin{aligned}
a_{n+m}(t) & =\left\|t x_{n+m}-u+(1-t) v\right\| \\
& \leqslant b_{n, m}+\left\|u-S_{n, m}\left(t x_{n}+(1-t) v\right)\right\| \\
& \leqslant b_{n, m}+\left\|S_{n, m}\left(t x_{n}+(1-t) v\right)-S_{n, m} u\right\|+\left\|S_{n, m} u-u\right\| \\
& \leqslant b_{n, m}+a_{n}(t)+\left\|S_{n, m} u-u\right\| .
\end{aligned}
$$

Taking limsup as $m \rightarrow \infty$ and then the $\lim \inf$ as $n \rightarrow \infty$, we find that

$$
\limsup _{n \rightarrow \infty} a_{n}(t) \leqslant \liminf _{n \rightarrow \infty} a_{n}(t) \text {. }
$$

This proves that $\lim _{n \rightarrow \infty} a_{n}(t)$ for any $t \in[0,1]$. In view of Lemma 2.6, we see that $\omega_{w}\left(x_{n}\right) \subset(A+$ $B)^{-1}(0)$. This implies from Lemma 2.7 that $\omega_{w}\left(x_{n}\right)$ is a singleton set. This completes the proof.

If $\alpha_{n}=0$, then Theorem 3.1 is reduced to the following.

Corollary 3.2. Let $\mathrm{C}$ be a nonempty convex and closed subset of a real uniformly convex and q-uniformly smooth Banach space $\mathrm{E}$. Let $\mathrm{K}_{\mathrm{q}}$ be the smooth constant $\mathrm{E}$. Let $\mathrm{B}: \operatorname{Dom}(\mathrm{B}) \subset \mathrm{C} \rightarrow 2^{\mathrm{E}}$ be an $\mathrm{m}$-accretive operator and let $A: C \rightarrow E$ be an $\alpha$-inverse strongly accretive operator. Assume $(B+A)^{-1}(0) \neq \emptyset$. Let $\left\{x_{n}\right\}$ be a sequence defined by: $\mathrm{x}_{0} \in \mathrm{C}$ and

$$
x_{n+1} \approx\left(I+r_{n} B\right)^{-1}\left(x_{n}-r_{n} A x_{n}\right),
$$

where the criterion for the approximate computation of $x_{n+1}$ is $\left\|\left(I+r_{n} B\right)^{-1}\left(x_{n}-r_{n} A x_{n}\right)-x_{n+1}\right\| \leqslant e_{n}$, and $\left\{r_{n}\right\}$ is a real sequence satisfying the following restrictions: $\sum_{i=0}^{\infty} e_{n}<\infty, 0<r \leqslant r_{n} \leqslant r^{\prime}<2 \alpha$. Then $\left\{x_{n}\right\}$ converges weakly to some zero of $\mathrm{A}+\mathrm{B}$.

\section{Applications}

Theorem 4.1. Let $\mathrm{C}$ be a nonempty convex and closed subset of a real Hilbert space $\mathrm{E}$. Let $\mathrm{B}: \mathrm{Dom}(\mathrm{B}) \subset \mathrm{C} \rightarrow 2^{\mathrm{E}}$ be a monotone operator and let $\mathrm{A}: \mathrm{C} \rightarrow \mathrm{E}$ be an $\alpha$-inverse strongly monotone operator. Assume $(\mathrm{B}+\mathrm{A})^{-1}(0) \neq \emptyset$. Let $\left\{x_{n}\right\}$ be a sequence defined by: $x_{0} \in C$ and

$$
\left\{\begin{array}{l}
z_{n} \approx\left(I+r_{n} B\right)^{-1}\left(x_{n}-r_{n} A x_{n}\right), \\
x_{n+1}=\left(1-\alpha_{n}\right) z_{n}+\alpha_{n} x_{n}, \quad \forall n \geqslant 0,
\end{array}\right.
$$

where the criterion for the approximate computation of $z_{n}$ is $\left\|\left(I+r_{n} B\right)^{-1}\left(x_{n}-r_{n} A x_{n}\right)-z_{n}\right\| \leqslant e_{n}$, and $\left\{\alpha_{n}\right\}$ 
and $\left\{r_{n}\right\}$ are real sequences satisfying the following restrictions: $\sum_{i=0}^{\infty} e_{n}<\infty, 0 \leqslant \alpha_{n} \leqslant \alpha<1$, and $0<r \leqslant$ $\mathrm{K}_{\mathrm{q}} \mathrm{r}_{\mathrm{n}}^{\mathrm{q}-1} \leqslant \mathrm{r}^{\prime}<\mathrm{q} \alpha$. Then $\left\{x_{\mathrm{n}}\right\}$ converges weakly to some zero of $\mathrm{A}+\mathrm{B}$.

Let $F$ be a bifunction of $C \times C$ into $\mathbb{R}$, where $\mathbb{R}$ denotes the set of real numbers. We consider the following equilibrium problem in the terminology of Blum and Oettli [5].

$$
\text { Find } x \in C \text { such that } F(x, y) \geqslant 0, \forall y \in C \text {. }
$$

In this paper, the set of such an $x \in C$ is denoted by $\operatorname{EP}(F)$, i.e., $\operatorname{EP}(F)=\{x \in C: F(x, y) \geqslant 0, \forall y \in C\}$.

To study the equilibrium problem, we assume that $F$ satisfies the following conditions:

(C1) $\mathrm{F}$ is a monotone function;

(C2) $F(x, x)=0$ for all $x \in C$;

(C3) for each $x, y, z \in C, F(x, y) \geqslant \lim \sup _{t \downarrow 0} F(t z+(1-t) x, y)$;

(C4) for each $x \in C, y \mapsto F(x, y)$ is lower semi-continuous and convex.

Lemma 4.2 ([26]). Let $\mathrm{F}$ be a bifunction from $\mathrm{C} \times \mathrm{C}$ to $\mathbb{R}$ which satisfies $(\mathrm{C} 1),(\mathrm{C} 2),(\mathrm{C} 3)$, and $(\mathrm{C} 4)$, and let $\mathrm{B}_{\mathrm{F}}$ be a multivalued mapping of $\mathrm{H}$ into itself defined by

$$
B_{F} x= \begin{cases}\{z \in H:\langle y-x, z\rangle \leqslant F(x, y), \forall y \in C\}, & x \in C, \\ \emptyset, & x \notin C .\end{cases}
$$

Then $\mathrm{B}_{\mathrm{F}}$ is a maximal monotone operator with domain $\mathrm{D}\left(\mathrm{B}_{\mathrm{F}}\right)$, which is in $\mathrm{C}$ and $\mathrm{EP}(\mathrm{F})=\mathrm{B}_{\mathrm{F}}^{-1}(0)$.

Corollary 4.3. Let $\mathrm{E}$ be a real Hilbert space and let $\mathrm{C}$ be a closed convex subset of $\mathrm{E}$. Let $\mathrm{F}$ be a bifunction from $\mathrm{C} \times \mathrm{C}$ to $\mathbb{R}$ which satisfies $(\mathrm{C} 1),(\mathrm{C} 2),(\mathrm{C} 3)$, and $(\mathrm{C} 4)$ and let $\mathrm{B}_{\mathrm{F}}$ be defined in Lemma 4.2. Let $\left\{\mathrm{x}_{\mathrm{n}}\right\}$ be a sequence generated in the following manner: $\mathrm{x}_{0} \in \mathrm{C}$ and

$$
\left\{\begin{array}{l}
z_{n} \approx\left(I+r_{n} B_{F}\right)^{-1}, \\
x_{n+1}=\left(1-\alpha_{n}\right) z_{n}+\alpha_{n} x_{n}, \quad \forall n \geqslant 0,
\end{array}\right.
$$

where the criterion for the approximate computation of $z_{n}$ is $\left\|\left(I+r_{n} B_{F}\right)^{-1}-z_{n}\right\| \leqslant e_{n}$, and $\left\{\alpha_{n}\right\}$ and $\left\{r_{n}\right\}$ are real sequences satisfying the following restrictions: $\sum_{i=0}^{\infty} e_{n}<\infty, 0 \leqslant \alpha_{n} \leqslant \alpha<1$, and $0<r \leqslant r_{n} \leqslant r^{\prime}<2 \alpha$. Then $\left\{x_{n}\right\}$ converges weakly to some zero of $\mathrm{EP}(\mathrm{F})$.

Consider the optimization problem $\min _{x \in C} f(x)$, where $f: H \rightarrow R$ is a convex and differentiable function. Assume that the solution set $\Omega$ of the problem is not empty and let $\Omega$ denote its set of solutions. The gradient projection algorithm is popular to solve the problem. It is known that the minimization problem is equivalent to the variational inequality problem

$$
\langle\nabla y-x, f(x)\rangle \geqslant 0, \quad \forall y \in C .
$$

It is also known that if $\nabla f$ is $\frac{1}{\alpha}$-Lipschitz continuous, then it is also $\alpha$-inverse strongly monotone. By taking $A=\nabla f$, we find the following result immediately.

Corollary 4.4. Let $\mathrm{E}$ be a real Hilbert space and let $\mathrm{C}$ be a closed convex subset of $\mathrm{E}$. Assume that $\mathrm{f}: \mathrm{H} \rightarrow \mathrm{R}$ is convex and differentiable with $\frac{1}{\alpha}$-Lipschitz continuous gradient $\nabla \mathrm{f}$ such that $\Omega \neq \emptyset$. Let $\left\{x_{n}\right\}$ be a sequence generated in the following manner: $\mathrm{x}_{0} \in \mathrm{C}$ and

$$
\left\{\begin{array}{l}
z_{n} \approx \operatorname{Proj}_{C}\left(x_{n}-r_{n} \nabla f\left(x_{n}\right)\right), \\
x_{n+1}=\left(1-\alpha_{n}\right) z_{n}+\alpha_{n} x_{n}, \quad \forall n \geqslant 0,
\end{array}\right.
$$

where the criterion for the approximate computation of $z_{n}$ is $\left\|\operatorname{Proj}_{C}\left(x_{n}-r_{n} \nabla f\left(x_{n}\right)\right)-z_{n}\right\| \leqslant e_{n}$, and $\left\{\alpha_{n}\right\}$ and $\left\{r_{n}\right\}$ are real sequences satisfying the following restrictions: $\sum_{i=0}^{\infty} e_{n}<\infty, 0 \leqslant \alpha_{n} \leqslant \alpha<1$, and $0<r \leqslant r_{n} \leqslant$ $r^{\prime}<2 \alpha$. Then $\left\{x_{n}\right\}$ converges weakly to some solution of $\Omega$. 
Let $\mathrm{H}_{1}$ and $\mathrm{H}_{2}$ be two Hilbert spaces. Let $\mathrm{C}$ be a nonempty closed convex subset of $\mathrm{H}_{1}$ and let $\mathrm{Q}$ be a nonempty closed convex subset of $\mathrm{H}_{2}$.

The split feasibility problem (SFP) consists of finding a point $x$ satisfying the property: $x \in C$ and $A x \in Q$, where $A: H_{1} \rightarrow H_{2}$ is a bounded linear operator. To solve the SFP, it is very useful to investigate the following convexly constrained minimization problem: $\min _{x \in C} f(x)$, where $f(x)=\frac{1}{2}\left\|\left(I-P_{Q}\right) A x\right\|^{2}$. If the solution set $\Omega$ of the SFP is nonempty, then $C \cap(\nabla f)^{-1}(0) \neq \emptyset$.

Corollary 4.5. Let $\mathrm{H}_{1}$ and $\mathrm{H}_{2}$ be two Hilbert spaces. Let $\mathrm{C}$ be a nonempty closed convex subset of $\mathrm{H}_{1}$ and let $\mathrm{Q}$ be a nonempty closed convex subset of $\mathrm{H}_{2}$. Let $\mathrm{A}: \mathrm{H}_{1} \rightarrow \mathrm{H}_{2}$ be a bounded linear operator and let $\mathrm{A}^{*}$ be the adjoint operator of A. Suppose that the SFP is consistent, i.e., $\Omega \neq \emptyset$. Let $\left\{x_{n}\right\}$ be a sequence generated in the following manner: $\mathrm{x}_{0} \in \mathrm{C}$ and

$$
\left\{\begin{array}{l}
z_{n} \approx \operatorname{Proj}_{C}\left(x_{n}-r_{n} A^{*}\left(I-\operatorname{Proj}_{Q}\right) A x\right), \\
x_{n+1}=\left(1-\alpha_{n}\right) z_{n}+\alpha_{n} x_{n}, \quad \forall n \geqslant 0,
\end{array}\right.
$$

where the criterion for the approximate computation of $z_{n}$ is $\left\|\operatorname{Proj}_{C}\left(x_{n}-r_{n} A^{*}\left(I-\operatorname{Proj}_{Q}\right) A x\right)-z_{n}\right\| \leqslant e_{n}$, $\left\{\alpha_{n}\right\}$ and $\left\{r_{n}\right\}$ are real sequences satisfying the following restrictions: $\sum_{i=0}^{\infty} e_{n}<\infty, 0 \leqslant \alpha_{n} \leqslant \alpha<1$ and $0<r \leqslant r_{n} \leqslant r^{\prime}<2 \alpha$. Then $\left\{x_{n}\right\}$ converges weakly to some solution of $\Omega$.

Proof. Let $f(x)=\frac{1}{2}\left\|\left(I-P_{Q}\right) A x\right\|^{2}$. According to [8], we have $\nabla f=A^{*}\left(I-\operatorname{Proj}_{Q}\right) A$, which is $\frac{1}{\alpha}$-Lipschitz continuous with $\alpha=\frac{1}{\|A\|^{2}}$. From Corollary 4.4, we find the desired conclusion immediately.

\section{Acknowledgment}

The authors thank the editor and the referees for careful reading and efforts to this paper.

\section{References}

[1] D. E. Alspach, A fixed point free nonexpansive map, Proc. Amer. Math. Soc., 82 (1981), 423-424. 2.1, 2.2

[2] I. K. Argyros, S. George, On the convergence of inexact Gauss-Newton method for solving singular equations, J. Nonlinear Funct. Anal., 2016 (2016), 22 pages. 1

[3] B. A. Bin Dehaish, A. Latif, H. O. Bakodah, X.-L. Qin, A regularization projection algorithm for various problems with nonlinear mappings in Hilbert spaces, J. Inequal. Appl., 2015 (2015), 14 pages. 1

[4] B. A. Bin Dehaish, X.-L. Qin, A. Latif, H. O. Bakodah, Weak and strong convergence of algorithms for the sum of two accretive operators with applications, J. Nonlinear Convex Anal., 16 (2015), 1321-1336. 1

[5] E. Blum, W. Oettli, From optimization and variational inequalities to equilibrium problems, Math. Student, 63 (1994), 123-145. 4

[6] F. E. Browder, Nonexpansive nonlinear operators in a Banach space, Proc. Nat. Acad. Sci. U.S.A., 54 (1965), 1041-1044. 2.7

[7] R. E. Bruck, A simple proof of the mean ergodic theorem for nonlinear contractions in Banach spaces, Israel J. Math., 32 (1979), 107-116. 2.6

[8] C. Byrne, A unified treatment of some iterative algorithms in signal processing and image reconstruction, Inverse Problems, 20 (2004), 103-120. 4

[9] S. Y. Cho, B. A. Bin Dehaish, X.-L. Qin, Weak convergence of a splitting algorithm in Hilbert spaces, J. Appl. Anal. Comput., 7 (2017), 427-438. 1

[10] S. Y. Cho, S. M. Kang, Approximation of common solutions of variational inequalities via strict pseudocontractions, Acta Math. Sci. Ser. B Engl. Ed., 32 (2012), 1607-1618. 1

[11] S. Y. Cho, W.-L. Li, S. M. Kang, Convergence analysis of an iterative algorithm for monotone operators, J. Inequal. Appl., 2013 (2013), 14 pages. 2

[12] J. García Falset, W. Kaczor, T. Kuczumow, S. Reich, Weak convergence theorems for asymptotically nonexpansive mappings and semigroups, Nonlinear Anal., 43 (2001), 377-401. 2.8

[13] S.-P. Han, G. Lou, A parallel algorithm for a class of convex programs, SIAM J. Control Optim., 26 (1988), 345-355. 1

[14] T. Kato, Nonlinear semigroups and evolution equations, J. Math. Soc. Japan, 19 (1967), 508-520. 2

[15] S.-T. Lv, Convergence analysis of a Halpern-type iterative algorithm for zero points of accretive operators, Commun. Optim. Theory, 2016 (2016), 9 pages. 1

[16] B. Martinet, Régularisation d'inéquations variationnelles par approximations successives, (French) Rev. Française Informat. Recherche Opérationnelle, 4 (1970), 154-158. 1 
[17] B. Martinet, Détermination approchée d'un point fixe d'une application pseudo-contractante, Cas de l'application prox, (French) C. R. Acad. Sci. Paris Sér. A-B, 274 (1972), 163-165. 1

[18] G. B. Passty, Ergodic convergence to a zero of the sum of monotone operators in Hilbert space, J. Math. Anal. Appl., 72 (1979), 383-390. 1

[19] X.-L. Qin, S.-S. Chang, Y. J. Cho, Iterative methods for generalized equilibrium problems and fixed point problems with applications, Nonlinear Anal. Real World Appl., 11 (2010), 2963-2972. 1

[20] X.-L. Qin, S. Y. Cho, Convergence analysis of a monotone projection algorithm in reflexive Banach spaces, Acta Math. Sci. Ser. B Engl. Ed., 37 (2017), 488-502. 1

[21] X.-L. Qin, J.-C. Yao, Weak convergence of a Mann-like algorithm for nonexpansive and accretive operators, J. Inequal. Appl., 2016 (2016), 9 pages. 1, 2.4

[22] R. T. Rockafellar, Augmented Lagrangians and applications of the proximal point algorithm in convex programming, Math. Oper. Res., 1 (1976), 97-116. 1

[23] R. T. Rockafellar, Monotone operators and the proximal point algorithm, SIAM J. Control Optimization, 14 (1976), 877-898. 1

[24] D. R. Sahu, J. C. Yao, A generalized hybrid steepest descent method and applications, J. Nonlinear Var. Anal., 1 (2017), 111-126. 2

[25] W. Takahashi, Weak and strong convergence theorems for families of nonlinear and nonself mappings in Hilbert spaces, J. Nonlinear Var. Anal., 1 (2017), 1-23. 1, 2.3

[26] S. Takahashi, W. Takahashi, M. Toyoda, Strong convergence theorems for maximal monotone operators with nonlinear mappings in Hilbert spaces, J. Optim. Theory Appl., 147 (2010), 27-41. 4.2

[27] H. K. Xu, Inequalities in Banach spaces with applications, Nonlinear Anal., 16 (1991), 1127-1138. 2.5

[28] S. Yang, Zero theorems of accretive operators in reflexive Banach spaces, J. Nonlinear Funct. Anal., 2013 (2013), 12 pages. 2 